\title{
The Accuracy of Fetal Head to Perineum Distance and Cervical Length in Predicting the Outcomes of Labor Induction
}

\author{
Original Gasser Adly El-Bishry, Abdel- Latif Galal El Kholy, Mohamed Samir Sweed, \\ Article Nada Hassan Hanafy Hassan* \\ Department of Obstetrics and Gynecology, Faculty of Medicine, Ain-Shams University, \\ Cairo, Egypt
}

\begin{abstract}
Background: Induction of labor is defined as the process of artificially stimulating the uterus to start labor. It is usually performed by administering oxytocin or prostaglandins to the pregnant woman or by manually rupturing the amniotic membranes.

Aim: The aim of the study is to assess the accuracy of fetal head to perineum distance and cervical length in predicting the outcomes of labor induction.

Patients and Methods: This is a prospective, observational study aimed to assess the accuracy of fetal-head to perineum distance and cervical length measurement in predicting the outcomes of labor induction. The study was performed at Ain Shams University Maternity Hospital from December 2017 to July 2018, 112 pregnant women who met inclusion criteria and admitted for labor induction at term (between 37-41 weeks).

Results: In predicting the outcomes of labor either vaginal delivery or CS, Bishop Score had low diagnostic performance while cervical length, FHPD and posterior cervical angle had moderate diagnostic performance. The mean for pain perception among women who had vaginal examination was 3.6 \pm 0.9 (range: 2.0-5.0) which is significantly higher than that among women who had perineal ultrasound 1.0 \pm 0.6 (range: $0.0-2.0$ ).

Conclusion: It can be concluded that, based on this study, the FHPD, CL and posterior cervical angle are useful in predicting the outcome of labor induction in comparison to Bishop Score. Ultrasound examination is better tolerated by women than pelvic examination.
\end{abstract}

Key Words:Cervical length in predicting, fetal head to perineum distance, outcomes of labor induction

Received: 1 October 2019, Accepted: 2 October 2019

Corresponding Author: Nada Hassan Hanafy Hassan, Department of Obstetrics and Gynecology, Faculty of Medicine, Ain-Shams University, Cairo, Egypt, Tel.: 01001976841, E-mail: nh912720@gmail.com

ISSN: 2090-7625, February 2020, Vol.10, No. 1

\section{INTRODUCTION}

Over the years, various professional societies have recommended the use of induction of labor in circumstances in which the risks of waiting for the onset of spontaneous labor are judged by clinicians to be greater than the risks associated with shortening the duration of pregnancy by induction. These circumstances generally include gestational age of 41 completed weeks or more, prelabour rupture of amniotic membranes, hypertensive disorders, maternal medical complications, fetal death, fetal growth restriction, chorioamnionitis, multiple pregnancy, vaginal bleeding and other complications ${ }^{[1]}$.

The goal of labor induction is to achieve a successful vaginal delivery. Before induction, there are several clinical elements that need to be considered to estimate the success of induction and minimize the risk of Caesarean Section. Factors that have been shown to influence success rates of induction include the Bishop score, parity, body mass index, maternal age and estimated fetal weight ${ }^{[2]}$.

Assessment of cervical status is fundamental for the clinician to estimate the likelihood of a successful vaginal delivery. Of the Bishop score criteria for predicting successful induction, the most important is cervical dilatation, followed by effacement, station, and position, with the least important being consistency ${ }^{[3]}$.

Transvaginal ultrasonography is a well-known objective technique for assessing the entire length of the cervix and the morphological characteristics of the internal os even when the external os is closed ${ }^{[4]}$.

Several studies have compared the ability of the Bishop score to predict successful labor induction with ultrasound assessment of the cervix with conflicting results. Peregrine et al. reported cervical length $>1 \mathrm{~cm}$ to be 
a predictor for Caesarean Section with induction of labor ${ }^{[5]}$. In contrast, Hatfield et al. found that cervical length was not predictive of successful labor induction ${ }^{[6]}$. Rozenberg et al. reported that the Bishop score was a better predictor of time interval from induction to delivery ${ }^{[7]}$.

\section{AIM OF THE WORK}

The aim of this study is to assess the accuracy of fetal head to perineum distance and cervical length in predicting the outcomes of labor induction.

\section{PATIENTS AND METHODS}

Study design: This is a prospective, observational study.

Study Setting: This study was performed at the labor ward at Ain-Shams University Maternity Hospital.

Population: The study subjects were 112 singleton pregnant women admitted for induction of labor at term (between 37-41 weeks).

\section{Selection of Patient:}

\section{Inclusion Criteria:}

- Maternal age (20-35) years old.

- Body Mass Index (18-30).

- Term singleton pregnancy with gestational age (37-41) weeks.

- Living fetus with vertex presentation.

- Reactive CTG.

- Intact amniotic membranes.

- Indication for medical induction of labor as (preeclampsia, diabetes, fetal Intrauterine Growth Restriction and oligohydroaminos).

\section{Exclusion criteria:}

- Extremes of reproductive age (less than 20 years old or more than 35 years old).

- Body Mass Index (<18 - >30).

- Multiple pregnancies.

- Rupture of membranes.

- Intrauterine fetal death.

- Contraindication for vaginal delivery like macrosomia (more than $4 \mathrm{KG}$ ), malpresentations, placenta previa, cord prolapse, vasa previa, uterine fibroids and active genital herpes.

- Polyhydramnios.

- Any sign of fetal distress as abnormal CTG or low biophysical profile.

- History of scarred uterus.
- Contraindication for the use of prostaglandins like history of asthma, epilepsy or increased intra-ocular pressure.

Sample size Estimation: The required sample size was calculated using the Power Analysis and Sample Size (PASSC) software version 11.0.10 (NCSSC), LLC, Kaysville, Utah).

\section{Study methods:}

\section{All women were submitted to:}

- History taking with emphasis on maternal age, parity, gestational age, obstetric, medical and operative histories, and verbal consents was obtained before inclusion in the study.

- Physical examination: General and abdominal examination.Vaginal examination to ensure vertex presentation and intact membranes and to calculate Bishop score (position, consistency, effacement, dilatation and station).

- Sonographic examinations: All ultrasound examinations were performed by experienced sonographer using a Medison SonoAce R5 ultrasound machine in labour ward at Ain-Shams University Maternity Hospital (Figure 1).

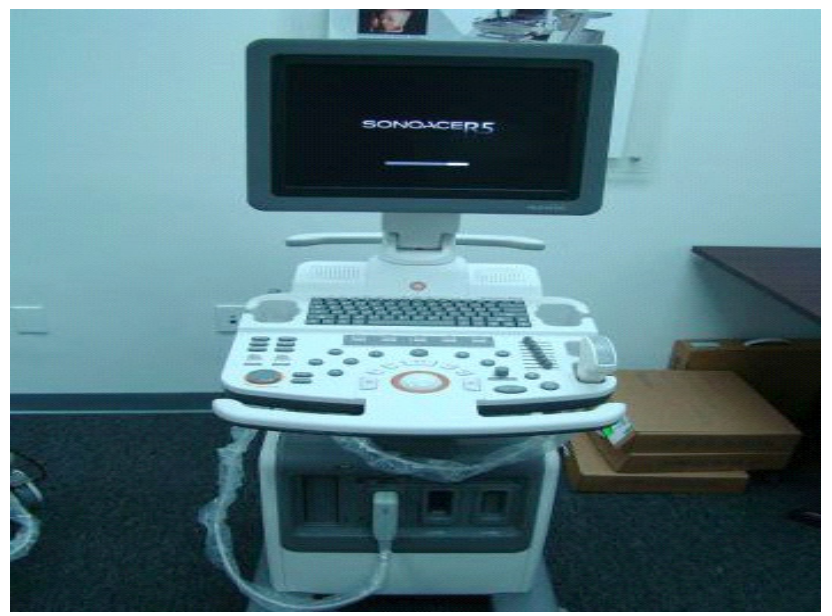

Fig. 1: Medison SonoAce R5 ultrasound machine at fetal medicine unit, Ain-Shams Maternity Hospital

Confirmation of intrauterine living pregnancy, placenta site, fetal presentation, liquor amount and gestational age.

Foetal head-perineal distance (FHPD) was measured with the patient in the lithotomy position with an empty bladder and a transverse convex probe on the skin of the perineum. Three measurements were obtained by single operator ( $\mathrm{Dr} /$ Ahmed Yassin) and the mean was the used value (Figures 2 and 3). 


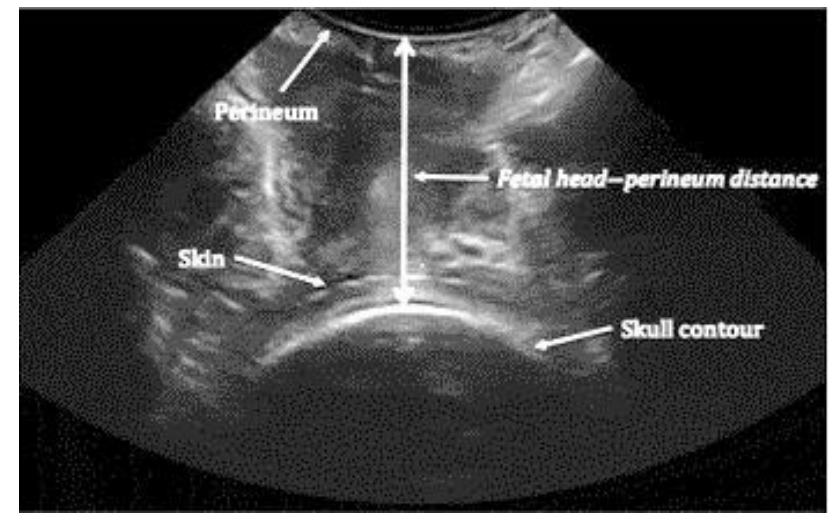

Fig. 2: Measurement of FHPD (Hassan et al., 2013)
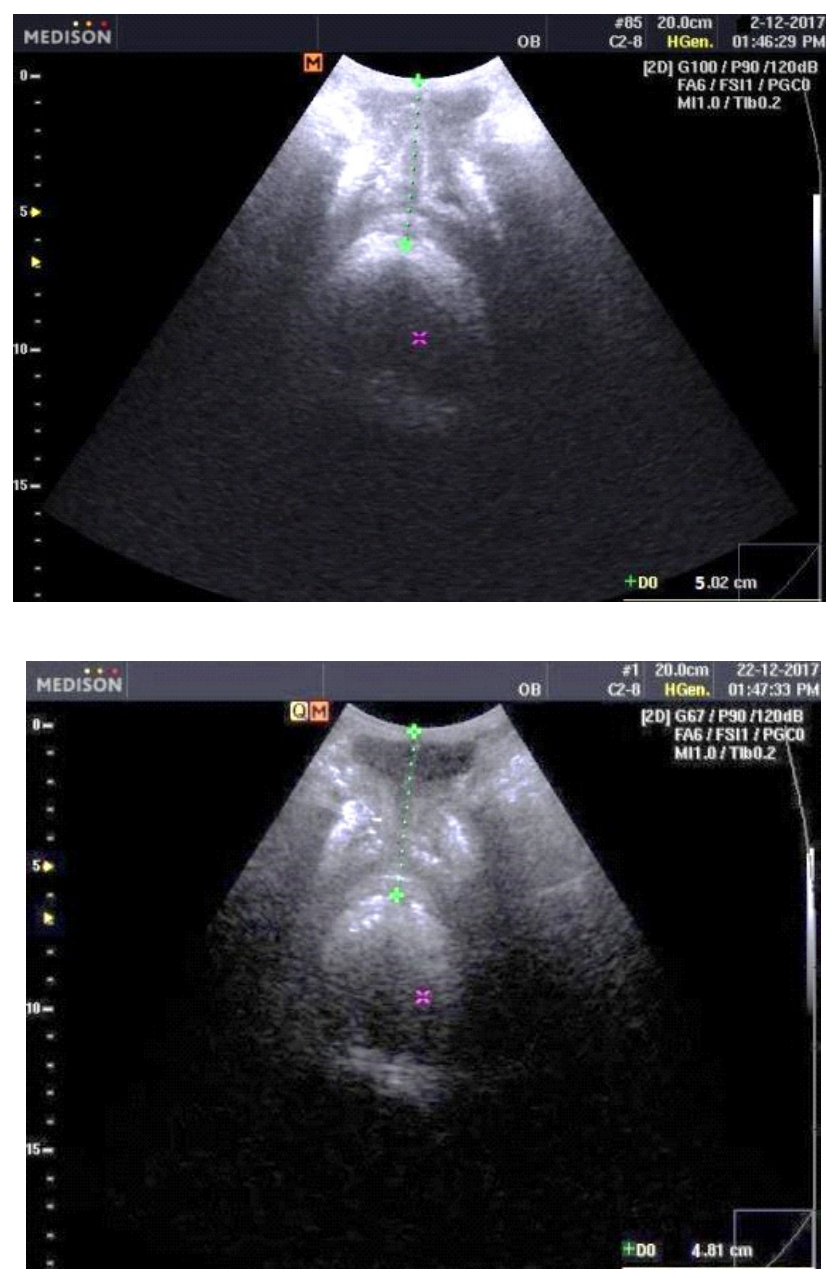

Fig. 3: FHPD measurement taken at fetal medicine unit (Ain-Shams Maternity Hospital)
Cervical length (CL) was measured by endovaginal ultrasound measuring the length between internal os and external os. Three measurements were obtained and the minimum value was used as the value (Figures 4 and 5).

\section{Measurement of the Cervix}

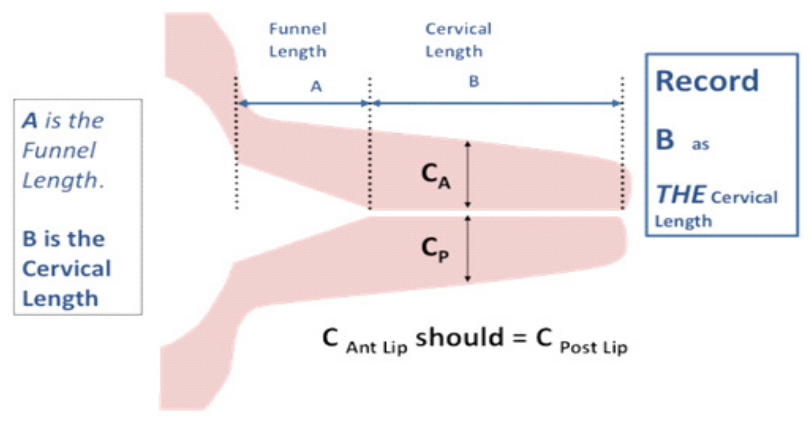

Fig. 4: Measurement of the cervical length (Berghella et al., 1997)

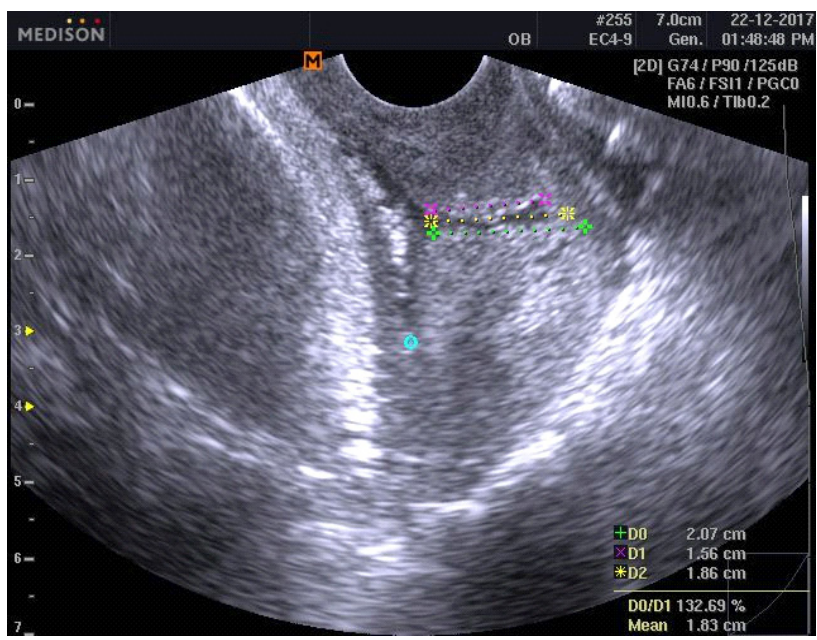

Fig. 5: Measurement of the cervical length taken at fetal medicine unit (Ain-Shams Maternity Hospital)

The wedging pattern was obtained by analyzing the image of the cervix obtained by Transvaginal ultrasound and determining whether the shape of the internal os resembled the letter $\mathrm{U}, \mathrm{V}$ or $\mathrm{T}$. The presence of cervical dilatation was defined as a hypoechoic band occupying the cervical length. Funnelling is incomplete dilatation of the internal os as $\mathrm{T}$ means no funnelling while $\mathrm{U}$ means complete funnelling (Figure 6). 

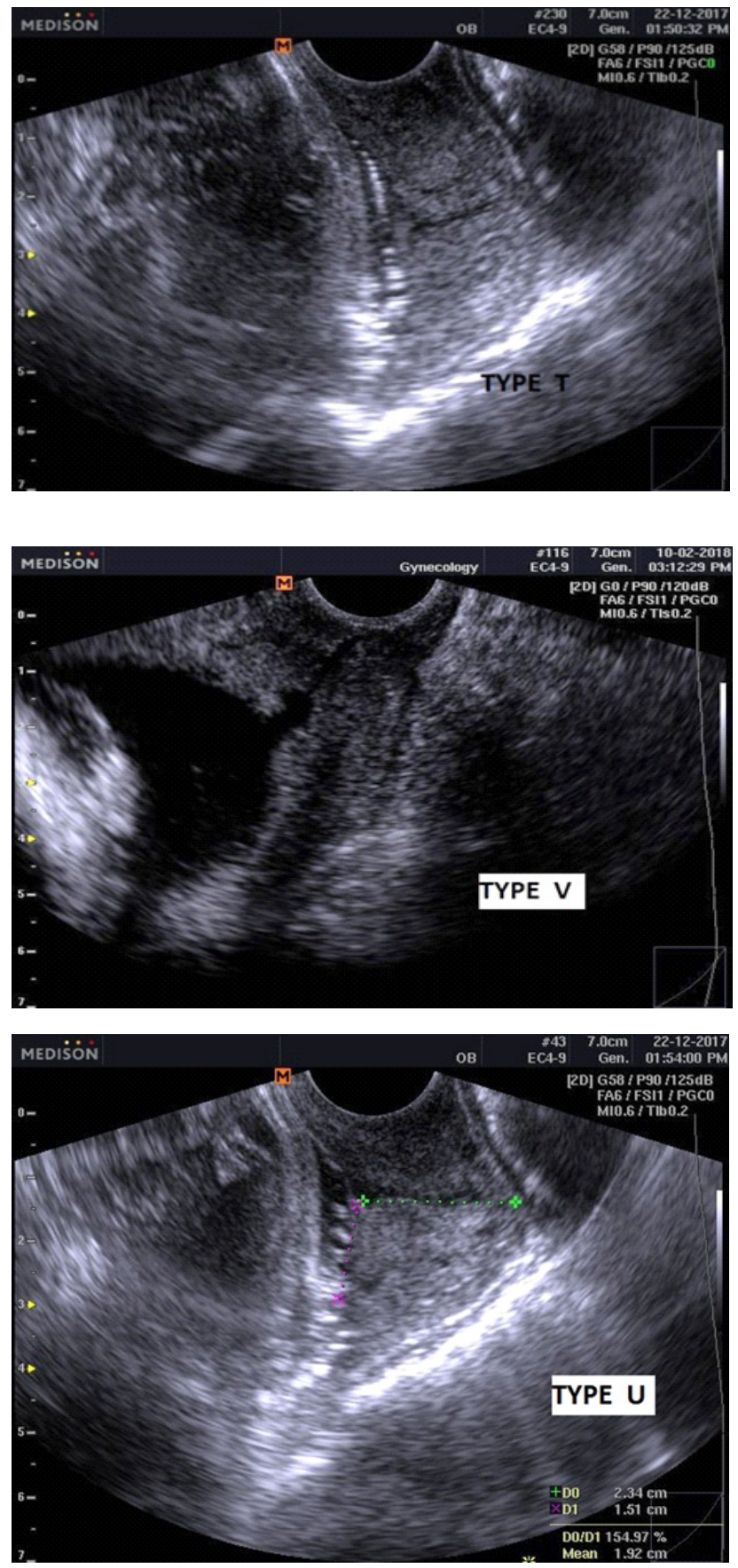

Fig. 6 : Wedging pattern of (T), (V) and (U) respectively taken at fetal medicine unit (Ain-Shams Maternity Hospital)

The posterior cervical angle was measured by Transvaginal ultrasound at the level of the internal os, as the angle between an imaginary line traversing the cervical canal and another tangential to the posterior uterine wall at its junction with the internal os (Figure 7).

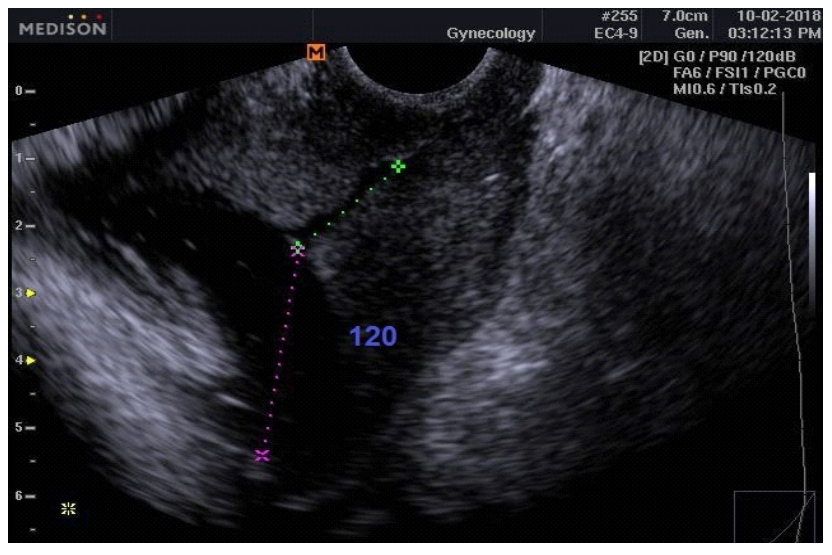

Fig.7: Measurement of posterior cervical angle taken at fetal medicine unit (Ain-Shams Maternity Hospital)

\section{Induction of labor:}

Using the induction protocol of Ain-Shams University Maternity Hospital, Dinoprostone, $3 \mathrm{mg}$ vaginal tablets

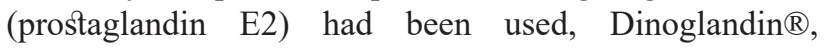
Rotabiogen for Pharmaceutical Investments and Chemicals, Alexandria, Egypt.

One vaginal suppository of Dinoglandin had been put in the posterior fornix then the patient had CTG to assess fetal well-being.

After 6 hours, reassessment of the cervix by bishop score.

When Bishop Score was less than 5 with cervical dilatation $<2-3 \mathrm{~cm}$ and effacement $50 \%$, another dose of Dinoglandin had been added. Reassessment again after 6 hours.

When there is no change in the Bishop score or the case didn't reach the active phase of labor $(4 \mathrm{~cm}$ or more cervical dilatation) and didn't develop regular effective uterine contractions (3-5 every 10 minutes, each lasting 40-60 seconds), the case had rest over-night.

In the early morning, reassessment of the Bishop score and fetal well-being by CTG. while the fetus was reactive, another cycle of Dinoglandin had been started and reassessment after 6 hours.

After $2^{\text {nd }}$ day of induction when the bishop score was still less than 8, CS had been done. 


\section{Ethical issues consideration:}

Verbal consent was taken from each participant after clarifying the nature and aim of the study reading to her information statement about the study. Participants were informed about objectives of the study and they were assured of voluntary participation. Confidentiality was maintained throughout by ensuring that no names that would identify the participant.

\section{Data collection:}

Recruitment data: following inclusion into the study, the case record form (CRF 1) was filled including demographic information, patient's age, parity, gestational age, obstetric, medical, operative histories and Bishop Score.

Women were contacted to investigator for ultrasound examination. Each woman had a case record form (CRF 2) in which the data was recorded.

\section{Data analysis:}

The collected data were coded, tabulated, and statistically analyzed using IBM SPSS statistics (Statistical Package for Social Sciences) software version 18.0, IBM Corp., Chicago, USA, 2009.

Descriptive statistics were done for quantitative data as minimum and maximum of the range as well as mean \pm SD (standard deviation) for quantitative normally distributed data, while it was done for qualitative data as number and percentage.

Inferential analyses were done for quantitative variables using independent t-test in cases of two independent groups with normally distributed data and paired t-test in cases of two dependent groups with normally distributed data.

In qualitative data, inferential analyses for independent variables were done using Chi square test for differences between proportions as well as Kappa test for agreement between paired categorical data. The level of significance was taken at $P$ value $<0.050$ is significant, otherwise is non-significant.
ROC curve was used to evaluate the performance of different tests differentiate between certain groups.

\section{Diagnostic characteristics were calculated as follows:}

- Sensitivity $=$ (True positive test / Total positive golden) x 100

- Specificity $=$ (True negative test $/$ Total negative golden) x 100

- Predictive positive value $=($ True positive test $/$ Total positive test) $\mathrm{x} 100$

- Predictive negative value $=($ True negative test $/$ Total negative test) $\mathrm{x} 100$

- $\mathrm{LR}+=$ (sensitivity/ 1-specificity)

- LR- = (1- sensitivity / specificity $)$

- Diagnostic accuracy $=$

([True positive test + True negative test] / Total cases) x 100

- Youden's index $=$ sensitivity + specificity -1

\section{RESULTS}

Among the studied 112 cases, 35 (31.3\%) underwent cesarean section (CS), while the remaining 77 (68.8\%) underwent vaginal delivery (VD). No significant difference was found between CS and VD cases regarding age, BMI, GA and parity (Table 1).

In predicting $\mathrm{CS}$, BISHOP score $\leq 7.0$ had low diagnostic characteristics. Cervical length $\geq 28.0$, fetal head-perineal distance $\geq 48.0 \mathrm{~mm}$ and posterior cervical angle $\leq 98.0$ had moderate diagnostic characteristics. Cervical length $\geq 28.0$ was the highest followed by fetal head-perineal distance $\geq 48.0 \mathrm{~mm}$ was the highest, then posterior cervical angle $\leq 98.0$ (Table 2 ).

Cervical length $\geq 28.0$, posterior cervical angle $\leq 98.0$ and fetal head-perineal distance $\geq 48.0$ $\mathrm{mm}$ were significant factors that predict CS. The equation is $\exp (-3.34+1.85$ [if $\mathrm{CL} \geq 28.0]+1.52$ $[$ if $\mathrm{PCA} \leq 98.0]+1.56$ [if FHPD $\geq 48.0 \mathrm{~mm}$ ]) $/ 1+$ $\exp (-3.34+1.85[$ if $\mathrm{CL} \geq 28.0]+1.52[$ if $\mathrm{PCA} \leq 98.0]+1.56$ [if FHPD $\geq 48.0 \mathrm{~mm}$ ] (Table 3).

Table 4 showed that pain perception during perineal US was significantly lower than that during vaginal examination. 
Table 1: Demographic characteristics among the studied cases

\begin{tabular}{|c|c|c|c|c|c|}
\hline Variables & Measures & $\begin{array}{c}\mathrm{CS} \\
(\mathrm{N}=35)\end{array}$ & $\begin{array}{c}\mathrm{VD} \\
(\mathrm{N}=77)\end{array}$ & $\begin{array}{c}\text { Total } \\
(\mathrm{N}=112)\end{array}$ & $P$ \\
\hline \multirow{2}{*}{$\begin{array}{l}\text { Age } \\
\text { (years) }\end{array}$} & Mean \pm SD & $28.5 \pm 3.0$ & $27.7 \pm 4.4$ & $27.9 \pm 4.0$ & \multirow{2}{*}{${ }^{\wedge} 0.325$} \\
\hline & Range & $23.0-35.0$ & $20.0-37.0$ & $20.0-37.0$ & \\
\hline \multirow{2}{*}{$\begin{array}{l}\text { BMI } \\
(\mathrm{kg} / \mathrm{m} 2)\end{array}$} & Mean \pm SD & $25.2 \pm 2.2$ & $24.9 \pm 2.4$ & $25.0 \pm 2.3$ & \multirow{2}{*}{$\wedge^{\wedge} 0.50$} \\
\hline & Range & $20.9-29.7$ & 18.9-29.9 & $18.9-29.9$ & \\
\hline \multirow{2}{*}{$\begin{array}{l}\text { GA } \\
\text { (weeks) }\end{array}$} & Mean \pm SD & $39.7 \pm 1.1$ & $39.9 \pm 1.0$ & $39.8 \pm 1.0$ & \multirow{2}{*}{$\wedge^{\wedge} 0.49 c$} \\
\hline & Range & $38.0-41.0$ & $37.0-41.0$ & $37.0-41.0$ & \\
\hline \multirow{2}{*}{$\begin{array}{l}\text { Parity } \\
(n, \%)\end{array}$} & Primi & $24(68.6 \%)$ & $40(51.9 \%)$ & $64(57.1 \%)$ & \multirow{2}{*}{$\# 0.099$} \\
\hline & Multi & $11(31.4 \%)$ & $37(48.1 \%)$ & $48(42.9 \%)$ & \\
\hline \multirow{2}{*}{$\begin{array}{l}\text { Indications of } \\
\text { induction }\end{array}$} & Post date & $26(74.3 \%)$ & $59(76.6 \%)$ & $85(75.6 \%)$ & \multirow{2}{*}{$\# 0.78 \mathrm{~s}$} \\
\hline & Oligohydr & $9(25.7 \%)$ & 18 (23.4\%) & $27(24.1 \%)$ & \\
\hline
\end{tabular}

${ }^{\wedge}$ Independent t-test, \#Chi square test.

Table 2 : Diagnostic characteristics of BISHOP score and US findings cutoff points in predicting CS

\begin{tabular}{|c|c|c|c|c|}
\hline Characters & Value & $95 \% \mathrm{CI}$ & Value & $95 \% \mathrm{CI}$ \\
\hline & \multicolumn{2}{|c|}{ BISHOP score $\leq 7.0$} & \multicolumn{2}{|c|}{ Cervical length $\geq 28.0$} \\
\hline Sensitivity & $91.4 \%$ & $76.9 \%-98.2 \%$ & $82.9 \%$ & $66.4 \%-93.4 \%$ \\
\hline Specificity & $32.5 \%$ & $22.2 \%-44.1 \%$ & $59.7 \%$ & $47.9 \%-70.8 \%$ \\
\hline DA & $50.9 \%$ & $41.3 \%-60.5 \%$ & $67.0 \%$ & $57.4 \%-75.6 \%$ \\
\hline Youden's index & $23.9 \%$ & $9.9 \%-37.9 \%$ & $42.6 \%$ & $26.0 \%-59.2 \%$ \\
\hline PPV & $38.1 \%$ & $27.7 \%-49.3 \%$ & $48.3 \%$ & $35.2 \%-61.6 \%$ \\
\hline NPV & $89.3 \%$ & $71.8 \%-97.7 \%$ & $88.5 \%$ & $76.6 \%-95.6 \%$ \\
\hline LR+ & 1.35 & $1.13-1.63$ & 2.06 & $1.51-2.81$ \\
\hline LR- & 0.26 & $0.09-0.82$ & 0.29 & $0.14-0.61$ \\
\hline \multirow[t]{2}{*}{ Kappa } & 5.13 & $1.43-18.37$ & 7.17 & $2.66-19.30$ \\
\hline & \multicolumn{2}{|c|}{ Posterior cervical angle $\leq 98.0$} & \multicolumn{2}{|c|}{ Fetal head-perineal distance $\geq 48.0 \mathrm{~mm}$} \\
\hline Sensitivity & $62.9 \%$ & $44.9 \%-78.5 \%$ & $68.6 \%$ & $50.7 \%-83.1 \%$ \\
\hline
\end{tabular}




\begin{tabular}{|c|c|c|c|c|}
\hline Specificity & $75.3 \%$ & $64.2 \%-84.4 \%$ & $71.4 \%$ & $60.0 \%-81.2 \%$ \\
\hline DA & $71.4 \%$ & $62.1 \%-79.6 \%$ & $70.5 \%$ & $61.2 \%-78.8 \%$ \\
\hline Youden's index & $38.2 \%$ & $19.5 \%-56.9 \%$ & $40.0 \%$ & $21.6 \%-58.4 \%$ \\
\hline PPV & $53.7 \%$ & $37.4 \%-69.3 \%$ & $52.2 \%$ & $36.9 \%-67.1 \%$ \\
\hline NPV & $81.7 \%$ & $70.7 \%-89.9 \%$ & $83.3 \%$ & $72.1 \%-91.4 \%$ \\
\hline LR+ & 2.55 & $1.60-4.06$ & 2.40 & $1.58-3.65$ \\
\hline LR- & 0.49 & $0.31-0.77$ & 0.44 & $0.26-0.73$ \\
\hline Kappa & 5.17 & $2.19-12.20$ & 5.45 & $2.29-13.00$ \\
\hline
\end{tabular}

CI: Confidence interval, YI: Youden's index, DA: Diagnostic accuracy, PPV: Positive Predictive value, NPV: Negative Predictive value, LR+: Positive likelihood ratio, LR-: Negative likelihood ratio, LR: Diagnostic odd ratio

Table 3: Logistic regression models for combining factors in predicting CS

\begin{tabular}{lcccc}
\hline Scores & $\beta$ & SE & $P$ & OR (95\% CI) \\
\hline $\begin{array}{l}\text { Cervical length } \geq 28.0 \\
\text { Posterior cervical } \\
\text { angle } \leq 98.0\end{array}$ & 1.85 & 0.55 & $0.001^{*}$ & $6.36(2.15-18.78)$ \\
$\begin{array}{l}\text { Fetal head-perineal } \\
\text { distance } \geq 48.0 \mathrm{~mm}\end{array}$ & 1.52 & 0.51 & $0.003 *$ & $4.57(1.68-12.43)$ \\
Constant & 1.56 & & & $4.77(1.77-12.88)$ \\
\hline
\end{tabular}

$\beta$ : Regression coefficient, SE: Standard error, OR: Odds ratio, CI: Confidence interval, *significant

Table 4: Vaginal examination and perineal US pain perception (VAS-10) among the studied cases

\begin{tabular}{lccc}
\hline Technique & Mean \pm SD & Range & $\wedge \mathrm{P}$ \\
\hline Vaginal examination & $3.6 \pm 0.9$ & $2.0-5.0$ & $<0.001^{*}$ \\
Perineal US & $1.0 \pm 0.6$ & $0.0-2.0$ & \\
Difference (Vaginal-US) & $2.6 \pm 0.5$ & $2.0-3.0$ & \\
\hline
\end{tabular}

Total $=90, \wedge$ Paired t-test, *Significant 


\section{DISCUSSION}

This was a prospective observational study of 112 pregnant women. Among the studied cases, 35 (31.3\%) underwent caesarean section, while the remaining 77 (68.8\%) underwent vaginal delivery. Among those cases, the average age was 27.9 years, the average BMI was $25 \mathrm{~kg} / \mathrm{m} 2$ and the mean gestational age was 39.2 weeks. $64(57.1 \%)$ of the women were primigravidae and $48(42.9 \%)$ were multigravidae. The indications for induction of labor were post term pregnancy in 85 cases and oligohydramnios in 27 cases.

The present study found that fetal head to perineum distance measurement by transperineal ultrasound is positive predictor of vaginal delivery after induction of labor.

This study agree with Alvarez et al. ${ }^{[8]}$ who also found that the FHPD is useful in predicting the result of the labor induction with a predictive value greater than that of cervical length and Bishop Score.

Eggebo et al. ${ }^{[9]}$ was a prospective study of 275 women admitted for induction of labor to evaluate fetal head to perineum distance measured by ultrasound as a predictive factor for induction of labor, and to compare this with cervical length, Bishop Score and occiput position.

The overall cesarean delivery rate was $13 \%$. One hundred and thirty (47\%) women were nulliparous. The cesarean delivery rate among nulliparous women was $22 \%$ compared with $5 \%$ among women with one or more previous vaginal deliveries $(P<0.01)$. The ROC curves indicated that fetal head-perineum distance $\leq 40 \mathrm{~mm}$, cervical length $\leq 25 \mathrm{~mm}$ and cervical angle $>90 \circ$ were the best cut-off levels for predicting vaginal delivery.

The results of our study agree with Eggebo et al..$^{[9]}$ who found that FHPD measurement can predict vaginal delivery after induction of labor, but with a predictive value similar to that of cervical length and Bishop.

The cutoff point of FHPD in this study was 47 $\mathrm{mm}$ which is lower in Alvarez et al. ${ }^{[8]}(45 \mathrm{~mm})$ and Eggebo et al. ${ }^{[9]}(40 \mathrm{~mm})$ most likely because of the higher proportion of multiparous women, which was related to the rate of successful induction as well as lowering and engagement of the head at the end of pregnancy.

The present study found out that cervical length measured by transvaginal ultrasound is positive predictor value of vaginal delivery after induction of labor.

Rane et al. ${ }^{[10]}$ was a prospective study of 604 singleton pregnancies to examine the value of preinduction sonographic assessment of cervical length, posterior cervical angle and occipital position in the prediction of the mode of delivery and to compare sonographic assessment with Bishop Score. Vaginal delivery occurred in $484(80.1 \%)$ women and this was within $24 \mathrm{~h}$ of induction in $388(64.2 \%)$. Cesarean section was performed in $120(19.9 \%)$. Prediction of the induction-to-delivery interval was provided by the occipital position, pre-induction cervical length, parity and posterior cervical angle.

Prediction of the likelihood of vaginal delivery within $24 \mathrm{~h}$ was provided by the occipital position, cervical length, posterior cervical angle and BMI. Prediction of the likelihood of Cesarean section was provided by the occipital position, cervical length, parity, maternal age and BMI. In the prediction of vaginal delivery within 24 hours, for a specificity of $75 \%$, the sensitivity for ultrasound findings was $89 \%$ and for the Bishop Score it was $65 \%$. The respective sensitivities for cesarean section were $78 \%$ and $53 \%$.

Rane et al. ${ }^{[10]}$ agreed with our kindly results as they found that cervical length and parity are good predictors of success of vaginal delivery with induction. This also agreed with Alvarez et al. ${ }^{[8]}$ and Eggebo et al. ${ }^{[9]}$.

Groeneveld et al. ${ }^{[11]}$ disagreed with our study as they found that cervical length measurement was not a predictive value of vaginal delivery after induction of labor. This may be due to the difference in the time to delivery interval which was too long (96 hours) in their study and also the different indications of induction with small number of cases in each.

Also in contrast to Groeneveld et al. ${ }^{[11]}$ with our results as they chose a longer interval (96 hours) between start of induction and vaginal delivery in order to avoid caesarean delivery as much as possible. Their caesarean delivery rate was $17.3 \%$ compared with $31.3 \%$ in our study. But that long period may be considered extra burden on the participants comparing with our interval 48 hours as prolonged trial of labour leads to maternal exhaustion and longer hospitalization with consequent increased morbidity and financial cost.

The present study found that Bishop Score had a positive predictive value in predicting the outcome of labor induction but with low diagnostic performance.

This agree with Alvarez et al. ${ }^{[8]}$, Eggebo et al. ${ }^{[9]}$ Rane et al. ${ }^{[10]}$ and Al-Adwy et al. ${ }^{[12]}$ but there were 
a difference in the cutoff points and this is mostly attributed to the subjective variables of digital examination.

Few studies have shown that the Bishop Score is better than the TVS parameters for prediction of successful induction of labour. In Chandra et al. ${ }^{[13]}$ which was a study of 122 women who had induction of labour at 41 or more weeks gestation comparing the TVS parameters with cervical digital examination, they observed that the maternal weight, cervical dilatation and effacement independently predicted successful outcome of labour induction. No cervical ultrasound measurements were shown to be significant in prediction of successful outcome. The difference of significance from our study may be the bias as a result of the confounding effects of the number of methods of induction used in the study.

In another study, Roman et al. ${ }^{[14]}$ they observed that when compared to Bishop Score, cervical length by ultrasound is not a better predictor for the outcome of labour induction. Rozenberg et al. ${ }^{[7]}$ in their study of 166 women induced with prostaglandins found the Bishop Score to be better than cervical length for predicting successful outcome of induced labour. They also found that once the Bishop Score is taken into account, further knowledge of cervical ultrasound did not improve the prediction of outcome.

Adwy et $a l .{ }^{[12]}$ was a prospective observational study of 70 pregnant women who admitted for induction of labor to determine the accuracy of the posterior cervical angle compared with the cervical length and the Bishop Score in predicting the outcome of induction of labor. This study is supporting the results of the current study but in the current study, the fetal head to perineum distance had a superior predictive value to the other parameters may be due to the high percentage of multigravidae $(58 \%)$ than our study $(42.9 \%)$ was related to the rate of successful induction as well as lowering and engagement of the head at the end of pregnancy.

Keepanasseril et al. ${ }^{[15]}$ was a prospective study conducted in 138 women who underwent cervical assessment with transvaginal sonography followed by digital cervical assessment using Bishop Score before induction of labour. Ultrasonographic parameters evaluated were cervical length, posterior cervical angle. To compare the efficacy of ultrasonographic cervical assessment with Bishop Score before induction of labour in predicting the success of labour induction in nulliparous women. Induction of labour was successful in $106(76.8 \%)$ of the women. The area under the receiver operating characteristic curve for cervical length and posterior cervical angle was greater than that of the Bishop Score in predicting a successful labour induction. The best cut-off point for the parameters in receiver operating characteristics curve was $3.0 \mathrm{~cm}$ for cervical length and $100^{\circ}$ for posterior cervical angle. Cervical length of $3.0 \mathrm{~cm}$ had a sensitivity of $84.9 \%$, and a specificity of $90.6 \%$ and a posterior cervical angle of $100^{\circ}$ with $65 \%$ and $72 \%$, respectively.

This study agreed also with Keepanasseril et al. ${ }^{[15]}$ who found that a posteriorcervical angle of 100 degrees had a positive predictive value in predicting successful labour induction in nulliparous women with sensitivity of $65 \%$ and specificity of $72 \%$ which is highly similar to the current study of $62.9 \%$ and $75.3 \%$, respectively.

As regard to wedging and funneling there is no significant diagnostic performance in predicting the outcomes of labor induction but in this study funneling (incomplete dilatation of the internal os) was more frequent in cases underwent vaginal delivery. This result is similar to Alvarez et al. ${ }^{[8]}$ and so this need more researches to find out its significance.

Funnelling was present in only $24.1 \%$ of the women in this study. The absence of funnelling can be explained by the phenomenon that towards the end of pregnancy head descends, so the funnelling may disappear or may be obscured by mucus or cervical glands in ultrasonography. So to refuse or accept the usefulness of funnelling as a predictor needs further studies.

ROC curve was calculated for quantitative variables related to the results of the induction of labour. The largest area under the curve was calculated for FHPD (0.794, $95 \%$ CI 0.704-0.884), followed by PCA $(0.759,95 \%$ CI $0.661-0.856)$ then CL $(0.720,95 \%$ CI 0.621-0.820) and lastly Bishop Score (0.676, $95 \%$ CI $0.573-0.780)$, although the difference is not statistically significant.

Tan et $a l^{[16]}$ was a prospective study which was performed on 249 women admitted for labor induction. To compare transvaginal sonography for cervical length measurement and digital examination for Bishop Score assessment in women undergoing labor induction at term, to assess their tolerability (in terms of pain) and ability to predict need for cesarean delivery. A 10 point visual analog scale (VAS) for procedure related pain was obtained.

Vaginal examination and perineal ultrasound pain perception was studied and results of pain perception 
during perineal US was significantly lower than that during vaginal examination and this matching the results of Alvarez et al. ${ }^{[8]}$ and Tan et al. ${ }^{[16]}$ and reporting its importance in daily practice although its higher cost and this need more studies to outweighs the benefits and tolerance to the cost.

There is no statistical difference between primigravidae and multigravidae and this need more research with larger number of cases.

In conclusion, this study had positive points over other studies in evaluation of pain perception and compliance of cases to ultrasound over vaginal examination but also this study need more research over to include more cases with different indications of induction of labor and cases with rupture of membranes.

This study did not mention the cost effectiveness of ultrasound examination over vaginal examination which is important factor for more research to know the tolerance to the cost to the cases in our country.

\section{CONCLUSION}

It can be concluded that, based on this study, the FHPD, $\mathrm{CL}$ and posterior cervical angle are useful in predicting the outcome of labor induction in comparison to Bishop Score.

The predictive value of FHPD, assessed by Area under Curve (AUC) is greater than that of PCA, CL and Bishop Score respectively.

Ultrasound examination is better tolerated by women than pelvic examination.

These predictive values can select pregnant women undergoing induction who have a risk of CS but it does not allow avoiding induction of labor with unfavourable prognosis because of false positive rates.

\section{RECOMMENDATIONS:}

More studies with larger sample size are still needed to confirm the accuracy of ultrasound measurements in predicting the outcomes of labor induction.

At the end of this study, we recommend using fetalhead to perineal distance, cervical length and posterior cervical angle to predict the outcome of induction of labor.

\section{CONFLICT OF INTEREST}

There are no conflicts of interests.

\section{REFERENCES}

1. Mozurkewich E, Chilimigras J, Koepke E, Keeton $\mathrm{K}$ and King VJ (2009): Indications for induction of labour. A best-evidence review. BJOG; 116(5):626-636.

2. Crane JM (2006): Factors predicting labor induction success: a critical analysis. Clinical Obstetrics and Gynecology; 49(3):573-584.

3. Laughon SK, Zhang J, Troendle J, Sun L and Reddy UM (2011): Using a simplified Bishop Score to predict vaginal delivery. The Green Journal; 117(4):805-811.

4. Jackson GM, Ludmir J and Bader TJ (1992): The accuracy of digital examination and ultrasound in the evaluation of cervical length. Obstet Gynecol; 79(2):214-218.

5. Peregrine E, O'Brien $P$, Omar $\mathrm{R}$ and Jauniaux E (2006): Clinical and ultrasound parameters to predict the risk of cesarean delivery after induction of labor. The Green Journal. 107 (2, part 1): 227-233.

6. Hatfield AS, Sanchez-Ramos L and Kaunitz AM (2007): Sonographic cervical assessment to predict the success of labour induction: a systematic review with metaanalysis AJOG; 197(2):186-192.

7. Rozenberg $\mathrm{P}$, Chevret S, Chastang C, Ville Y (2005): Comparison of digital and ultrasonographic examination of the cervix in predicting the interval from induction to delivery in women with low Bishop Score. BJOG; 112(2):192-196.

8. Alvarez-Colomo $\mathrm{C}$ and Gobernado-Tejedor JA (2016): The validity of ultrasonography in predicting the outcomes of labour induction. Archives of Gynecology and Obstetrics; 293(2): 311-316.

9. Eggebo TM, Okland I, Heien C, Gjessing LK, Romundstad P, Salvesen SA (2009): Can ultrasound measurements replace digitally assessed elements of the Bishop Score?. Acta Obstetricia et Gynecologica; 88: 325-331.

10. Rane SM, Guirgis RR, Higgins B \& Nicolaides KH (2004): The value of ultrasound in the prediction of successful induction of labor. Ultrasound in Obstetrics and Gynecology: The Official Journal 
of the International Society of Ultrasound in Obstetrics and Gynecology; 24(5): 538-549.

11. Groeneveld YJB, Bohnen AM \& Van Heusden AM (2010): Cervical length measured by transvaginal ultrasonography versus Bishop Score to predict successful labour induction in term pregnancies. Facts, views \& vision in Ob Gyn; 2(3): 187.

12. Al-Adwy AM, Sobh SM, Belal DS, Omran EF, Hassan A, Saad AH ... \& Nada AM (2018): Diagnostic accuracy of posterior cervical angle and cervical length in the prediction of successful induction of labor. International Journal of Gynecology \& Obstetrics; 141(1): 102-107.

13. Chandra S, Crane JM, Hutchens D \& Young DC (2001): Transvaginal ultrasound and digital examination in predicting successful labor induction. Obstetrics \& Gynecology; 98(1): 2-6.

14. Roman H, Verspyck E, Vercoustre L, Degre S, Col JY, Firmin JM \& Marpeau L (2004):
Does ultrasound examination when the cervix is unfavorable improve the prediction of failed labor induction?. Ultrasound in Obstetrics and Gynecology: The Official Journal of the International Society of Ultrasound in Obstetrics and Gynecology; 23(4): 357-362.

15. Keepanasseril A, Suri V, Bagga R \& Aggarwal, $N$ (2007): Pre-induction sonographic assessment of the cervix in the prediction of successful induction of labour in nulliparous women. Australian and New Zealand Journal of Obstetrics and Gynaecology; 47(5): 389-393.

16. Tan PC, Vallikkannu N, Suguna S, Quek KF \& Hassan J (2007): Transvaginal sonographic measurement of cervical length vs. Bishop Score in labor induction at term: tolerability and prediction of Cesarean delivery. Ultrasound in Obstetrics and Gynecology; 29(5): 568-573 